\title{
O Poder no Executivo: uma análise do papel da Presidência e dos Ministérios no presidencialismo de coalizão brasileiro (1995-2010)
}

\begin{tabular}{c} 
Mariana Batista \\
Doutoranda em Ciência Política \\
Universidade Federal de Pernambuco \\
\hline \hline
\end{tabular}

\begin{abstract}
Resumo: Qual o papel da Presidência e dos Ministérios na produção legislativa do Poder Executivo? Com base em uma abordagem transacional sobre a relação entre o Presidente e os ministros, busca-se, a partir da identificação da autoria das iniciativas legislativas do Executivo, elencar os fatores que influenciam o Presidente a delegar decisões legislativas para os ministérios ou centralizar as decisões na Presidência. As hipóteses, testadas através de um modelo logístico para eventos raros, são que o aumento da distância ideológica, do número de ministros envolvidos na decisão e da institucionalização da Presidência aumenta a chance de centralização, enquanto o aumento na força legislativa dos partidos dos ministros envolvidos diminui a chance de centralização. Os resultados indicam que tais fatores importam para entender o processo de formulação legislativa dentro do Executivo e a escolha que o Presidente faz.
\end{abstract}

Palavras-chave: presidentes; ministros; governo de coalizão; produção legislativa

Abstract: What is the role of the presidency and ministries in the legislative production of the Executive Branch? From a transactional approach to the relationship between the president and ministers we seek, through the identification of the authorship of the legislative initiatives of the Executive, evaluate the factors that influence the president to delegate legislative decisions to the ministries or centralize decisions in the presidency. The hypotheses tested using a logistic model for rare events is that the increase in ideological distance, the number of ministers involved in the decision and the institutionalization of the presidency increases the probability of centralization, while the increase in the legislative strength of the parties of the ministers involved decreases the probability of centralization. The results indicate that these factors matter to understand the process of legislative formulation within the Executive and the choice that the president does.

Keywords: presidents; ministers; coalition government; legislative production 
OPINIÃO PÚBLICA, Campinas, vol. 19, n², novembro, 2013, p. 449-772

\section{Introdução ${ }^{1}$}

Muito se argumenta em torno do presidencialismo de coalizão brasileiro e como este possibilitou a dominância legislativa do Executivo no país. A "combinação difícil" entre presidencialismo e multipartidarismo (MAINWARING, 1993) não gerou o entrave ou o imobilismo esperado no processo decisório e grande parte da explicação está na capacidade do Presidente de contornar as dificuldades de um governo minoritário através da formação de coalizões. O resultado é a aprovação da agenda do Presidente no Poder Legislativo, que conta com uma base de apoio razoavelmente consistente, transformando o Executivo no principal legislador de fato no país, sendo a origem de mais de $75 \%$ dos projetos aprovados pelos legisladores (FIGUEIREDO e LIMONGI, 2001).

Apesar de tal foco na dominância legislativa do Poder Executivo e no papel das coalizões para garantir tal sucesso, pouco se sabe sobre a dinâmica interna desse poder e como as coalizões de fato funcionam após a formação do governo. Exceções importantes são o argumento inovador desenvolvido por Amorim Neto (2006) sobre a formação e a importância do gabinete e as ideias pioneiras sobre a dinâmica interna do Executivo de Inácio (2006). O que a formação de uma coalizão governativa através da transferência do controle de pastas ministeriais para os partidos da base de fato significa? Da perspectiva do Poder Legislativo, a incorporação dos partidos da base no governo cimenta a relação entre o Presidente e a base e fortalece o apoio dos parlamentares à agenda do Presidente (AMORIM NETO, 2006). Contudo, ao apoiar a agenda do Executivo no Congresso, o que os partidos da coalizão recebem? Dito de outra forma, o que significa para os partidos da base o controle de pastas ministeriais?

$\mathrm{O}$ argumento desenvolvido no presente artigo é que, em troca do apoio do seu partido no Legislativo, o ministro busca influência no governo. Assim, o Presidente e os ministros estão envolvidos em uma troca: apoio legislativo por influência no governo. Com isto em mente, o ministro não pode ser visto como um funcionário regular do Presidente. Como representante do partido, o ministro tem uma ideologia, preferências políticas, projetos eleitorais e seu partido tem uma agenda política própria e isto pode afetar diretamente as decisões tomadas pelo governo.

O artigo busca exatamente avaliar a influência da coalizão ${ }^{2}$ no governo, focando no papel dos ministros na produção legislativa do Poder Executivo. O objetivo é identificar em que medida o poder dentro do Executivo é compartilhado entre o Presidente e os membros da coalizão. A problemática que se impõe é, tendo em vista tal dominância do Executivo, compreender o estágio anterior aos resultados da ação do Executivo. Isto é, para além de argumentar que o Executivo é forte na democracia atual ou que tem uma alta taxa de sucesso no legislativo, explicar o processo através do qual tais leis são construídas e propostas ao Congresso Nacional e o papel desempenhado pelas coalizões dentro do governo.

1 Versões anteriores deste artigo foram apresentadas no Workshop do Ronald Coase Institute, no $8^{\circ}$ Encontro da Associação Brasileira de Ciência Política e no $10^{\circ}$ Encontro Anual da ReDGob. Agradeço aos comentários recebidos nos referidos espaços a ao parecerista anônimo de Opinião Pública. Agradecimento fundamental à Magna Inácio pelo incentivo a esta pesquisa, Enivaldo Rocha pelo apoio metodológico, Lúcio Rennó pelos inúmeros comentários e sugestões e Marcus Melo pela orientação. Menção especial a Humberto Caetano do Ministério da Justiça pela dedicação e paciência na disponibilização dos dados solicitados e Argelina Figueiredo e Cesar Zucco pela disponibilização de seus bancos de dados. Qualquer erro remanescente é de minha total responsabilidade.

${ }^{2}$ Sobre a definição de coalizão: "a coalition is made up out of at least two political parties, and a government coalition refers to the sharing of executive office by different political parties" (MULleR, BERGMAN \& STROM, 2010, p. 6). Governos de coalizão são formados no presidencialismo brasileiro pela inclusão de outros partidos (base de governo) no controle de pastas ministeriais, além do partido do Presidente. 
BATISTA, M. O poder no Executivo: uma análise do papel da Presidência e dos Ministérios...

Para tanto, fortemente baseado no trabalho de Rudalevige (2002), o artigo busca identificar a autoria dos projetos legislativos dentro do Poder Executivo, se formulados pelos Ministérios ou pela Presidência. A ideia central é que o Presidente tem duas opções distintas à sua disposição para a formulação das iniciativas legislativas do Poder Executivo: ele pode delegar as decisões para os Ministérios ou pode centralizar as decisões na Presidência. Os ministros controlam pastas ministeriais e, nesse sentido, controlam a informação sobre aquele tema específico. Contudo, por representarem os diferentes partidos da coalizão, os ministros podem ter interesses diferentes dos interesses do Presidente ${ }^{3}$. A Presidência é o órgão de assistência direta que responde aos interesses do presidente. Porém, é um órgão que não apresenta o grau de especialização dos ministérios.

O objetivo é identificar sob quais condições o Presidente escolhe um curso de ação e não o outro. Ou seja, identificar sob quais condições o Presidente centraliza as decisões na Presidência, focando nos custos de transação de cada escolha específica: delegar ou centralizar. O foco está na distância ideológica entre o Presidente e os ministros envolvidos, o número de atores envolvidos na decisão, o grau de institucionalização da Presidência e a força dos partidos da coalizão. Espera-se que o aumento na distância ideológica, do número de ministros envolvidos na decisão e da institucionalização da Presidência aumente a chance de centralização, enquanto o aumento na força legislativa dos partidos dos ministros envolvidos diminua a chance de centralização.

$\mathrm{O}$ artigo analisa o presidencialismo de coalizão brasileiro com base na ideia geral de um Poder Executivo complexo que se constitui numa arena de articulação de interesses e de tomada de decisões sobre matérias legislativas anterior à tramitação no Poder Legislativo. Para tanto, está subdividido em mais duas seções além desta introdução e da conclusão. A próxima seção apresenta a estrutura analítica do artigo, tendo por base uma abordagem transacional. Em seguida, os principais resultados com base na autoria dos projetos legislativos do Executivo são apresentados. Por último, a conclusão.

\section{Uma abordagem transacional para o Poder Executivo}

A economia dos custos de transação trouxe três contribuições principais para o estudo das relações sociais: a transação específica entre os atores como unidade de análise; a identificação de custos associados a tais transações que não se relacionam com os custos de produção; e a identificação de modos de governança distintos para lidar com os custos de transação observados (COASE, 1937; 2005; WiLLIAMSON, 2002; 2005).

Um modelo analítico central para essa literatura é o que ficou conhecido como o problema de integração vertical ou "make or buy", que se constitui na base fundamental para a discussão mercado versus firma (WILLIAMSON, 2002). O dilema que se impõe é o seguinte: para produzir um bem final, "A" precisa de um subcomponente produzido por "B". Neste caso, "A" pode comprar o subcomponente em uma transação de mercado, ou assumir todo o processo de produção e produzir o subcomponente ele mesmo. Por que em alguns casos o mercado é usado enquanto em outros há hierarquia? A resposta está nos custos de transação.

\footnotetext{
${ }^{3}$ Não só os ministros dos demais partidos da coalizão, mas também os ministros do próprio partido do Presidente podem ter interesses divergentes. Nesse caso, a diferença é de grau, como será discutido adiante.
} 
Um mundo livre de custos de transação é substituído por outro onde as transações são custosas. Identificar toda a informação necessária, desenhar contratos e lidar com contratos necessariamente incompletos implicam custos e estes importam para as escolhas que os atores fazem, especialmente no que concerne a como as transações serão organizadas. De acordo com este argumento, há maneiras diferentes de organizar as transações e todas as formas são custosas. Então, as respectivas vantagens só podem ser avaliadas comparativamente. A análise procede como segue: identificação dos atores relevantes, da transação em questão, dos atributos da transação a fim de determinar a variação nos seus custos, e a análise comparativa das formas de organizar estas transações (MÉNARD, 2005).

Nas palavras de Williamson: "the overall object of the exercise essentially comes down to this: for each abstract transaction, identify the most economical governance structure - where by governance structure I refer to the institutional framework within which the integrity of a transaction is decided. Markets and hierarchies are two main alternatives" (WILLIAMSON, 1979, p. 235).

Atores políticos transacionam, e as transações também estão sujeitas a incertezas, riscos, oportunismo e todos os tipos de custos de transação. Nesse sentido, podemos falar de uma "política dos custos de transação" (NORTH, 1990). Alguns exemplos de abordagem transacional para trocas políticas de fundamental importância para o presente artigo são as contribuições de Weingast e Marshall (1988), Epstein e O'Halloran (1999) e Rudalevige (2002).

Com base no pressuposto de que as instituições são criadas para reduzir os custos de transação, deriva-se que as várias maneiras que uma legislatura pode ser organizada estão relacionadas com os custos associados às transações em questão. Com isso em mente, Weingast e Marshall falam de uma "organização industrial do Congresso" e colocam esta questão: por que Legislaturas, como as firmas, não estão organizadas como mercados? A análise é baseada nas preferências dos indivíduos, neste caso, os legisladores que buscam a reeleição, e nos custos de transação associados às trocas específicas entre os legisladores (WEINGAST e MARSHALL, 1988).

Os legisladores têm objetivos e preferências próprias, mas o Legislativo é uma instituição de tomada de decisão coletiva, e a regra da maioria obriga os parlamentares a buscarem os ganhos de troca. Uma troca política é o assunto aqui, então, como essas transações são organizadas e por quê? No modo de mercado, os votos são trocados livremente. No entanto, formas de troca através do mercado provavelmente serão ineficazes em capturar os ganhos de troca, já que problemas de observabilidade e de enfforcement dos acordos são prementes.

A instituição alternativa concebida pelo legislador para lidar com a ineficiência do modo de troca pelo mercado baseia-se no sistema de comissões. O sistema de comissões diminui o risco de oportunismo ex post. Ao invés de trocar votos, os legisladores trocam direitos especiais, quanto ao poder de agenda setting dos membros das comissões. "Because the exchange is institutionalized, it need not be renegotiated each new legislative session, and it is subject to fewer enforcement problems" (WEINGAST e MARSHALL, 1988, p. 157). Dessa forma, as diferentes formas que a relação entre os legisladores pode ser estabelecida têm por base os custos associados às trocas políticas em questão.

Epstein e O'Halloran têm por foco os custos associados às trocas políticas entre os poderes Executivo e Legislativo. No contexto de um sistema de separação de poderes, significando a 
BATISTA, M. O poder no Executivo: uma análise do papel da Presidência e dos Ministérios...

independência entre o Executivo e o Legislativo, "why does Congress delegate broad authority to the executive in some policy areas but not in others?" (EPSTEIN e O'HALLORAN, 1999, p. 7). Com esta pergunta, os autores aproximam um problema do tipo "make or buy": os legisladores podem escrever a legislação de forma detalhada no Congresso ou amplos poderes discricionários podem ser delegados ao Executivo. Duas estruturas de governança alternativas estão à disposição dos legisladores e a escolha é feita considerando os custos de transação:

"Congress examined its expected costs and benefits under alternative policy-making structures and selected the one that provided the most possible expected net political benefits, allocating decision-making authority across the branches and constraining it in such a way as to reap the benefits of delegation while minimizing the associated political costs" (EPSTEIN e O'HALLORAN, 1999, p. 4)

Na mesma direção, Rudalevige (2002) leva o argumento ainda mais longe, aplicando-o à análise do processo de tomada de decisão dentro do Poder Executivo. Dialogando com o trabalho seminal de Moe (1985) sobre a presidência politizada, Rudalevige (2002) analisa a escolha entre a produção centralizada das iniciativas legislativas do Presidente ou a delegação para os "departamentos". Em outras palavras, o presidente tem um problema "make or buy" com a escolha de formular a política dentro da Presidência ou delegá-la à burocracia. Há custos de transação associados às duas opções e o Presidente tem que escolher entre duas diferentes estruturas de governança.

Sob quais circunstâncias o Presidente vai escolher um governo centralizado sobre a delegação à burocracia? Segundo o autor:

\footnotetext{
"The cost of policy formulation to the president, then is a similar combination of price and a consideration of reliability. The latter hinges on whether the president trusts the information he is given, with trust, in turn, seen as an assessment of the expertise of the giver, weighted by the degree to which she shares presidential preferences. (....) Clearly the calculation of presidential transaction costs will not translate into dollars and cents or, for that matter, into any exact unit of measurement. We can instead aim to define shift parameters - to get a sense of which options are more costly than others under what circumstances, and thus to make predictions about effects, in direction and intensity, of different management environments on president's choices regarding centralization and policy formulation" (RUDALEVIGE, 2002, p. 31-32).
}

Tendo em mente este modelo, o autor propõe que uma maior centralização é esperada quando: a proposta envolver projetos com vários setores ou reorganização do governo, tendo em vista que as informações fornecidas pelos integrantes de departamentos e da burocracia mais ampla do governo em tais casos não são confiáveis; o Presidente tiver um forte apoio direto de uma burocracia institucionalizada, de modo que o custo da informação diminui e é mais confiável; a proposta requerer urgência, uma vez que a espera de uma resposta da burocracia não é viável; a proposta referir-se a um tema completamente novo, e não há burocracia especializada dentro do quadro mais amplo do Executivo. Em contraste, mais delegação é esperada quando: a complexidade da política aumenta, e conhecimento especializado é necessário, e também quando a maioria no Congresso é ideologicamente 
próxima do Presidente, dado que o Legislativo é também um principal para a burocracia (RUDALEVIGE, 2002).

Com estas abordagens em mente, o objetivo deste artigo é compreender o funcionamento de governos de coalizão em um sistema presidencialista. A estrutura política brasileira consiste em um presidencialismo multipartidário, o que significa que, apesar da separação e independência entre Executivo e Legislativo, o Presidente tem incentivos para formar coalizões para aprovar sua agenda legislativa e isto provou ser uma estratégia bem sucedida, considerando a dominância legislativa do Executivo no país (FIGUEIREDO e LIMONGI, 2001).

Outro aspecto dos governos de coalizão suficientemente enfatizado na literatura sobre os governos de coalizão em sistemas parlamentaristas, mas não levado a seu extremo em sistemas presidencialistas, é que as coalizões representam a participação de outros partidos dentro do governo, controlando cargos ministeriais, e isso significa muito mais do que apenas um emprego. O Presidente convida os partidos para se juntarem ao governo em troca de apoio político no Poder Legislativo. Mas este apoio é em troca de algo mais: o interesse do ministro em controlar um portfólio pode ser maior do que apenas postos de trabalho, incluindo também o controle do orçamento, a implementação de projetos em áreas eleitoralmente relevantes e, no caso do superlegislativo Executivo brasileiro, o controle da legislação. Resumindo, pode-se dizer que, em troca do apoio do seu partido no Legislativo, o ministro busca influência no governo. Assim, o Presidente e os ministros estão envolvidos em uma troca: apoio legislativo por influência no governo. Nessa perspectiva, o ministro não pode ser visto como um funcionário regular do Presidente. Como representante do partido, o ministro tem uma ideologia, preferências políticas, projetos eleitorais e seu partido tem uma agenda política própria.

O foco deste artigo é a relação entre o Presidente e o gabinete multipartidário no processo de produção legislativa dentro do Poder Executivo. No caso específico aqui analisado, para governar, o Presidente precisa de um subcomponente produzido pelos ministros, que é a informação para basear a produção de leis. Neste sentido, o Presidente tem um problema do tipo "make or buy": ele pode comprar esta informação livremente dos ministros setoriais, beneficiando-se da especialização e divisão do trabalho, ou ele pode integrar o processo de produção e construir as iniciativas legislativas na Presidência.

Claramente, as duas opções têm custos de transação. A livre negociação com os ministros setoriais aproxima-se da situação do mercado. A especialização derivada da divisão do trabalho dentro do governo e o controle da informação por parte dos ministros faz da "compra" uma opção atraente. No entanto, este controle exclusivo de informações pelos ministros oferece riscos para o controle do Presidente sobre as decisões do governo. O risco é maior quando o ministro é integrante dos demais partidos da base, já que podem ter interesses e projetos políticos e eleitorais diametralmente opostos aos do Presidente. Porém, a delegação irrestrita para ministros do mesmo partido do Presidente também traz custos, já que estes podem também ter uma agenda própria e conflitos no interior do mesmo partido são comuns. Dessa forma, a diferença é de grau e as duas opções constituem delegação.

Tendo isto em conta, a centralização pode tornar-se uma opção forte, mas apresenta custos. A centralização da tomada de decisão no interior da Presidência tem os benefícios do máximo controle sobre as decisões políticas, mas com a falta de conhecimento específico, a Presidência pode aumentar a 
BATISTA, M. O poder no Executivo: uma análise do papel da Presidência e dos Ministérios...

incerteza sobre os resultados e um esforço permanente no aumento da capacidade da Presidência tem altos custos de oportunidade.

Assim como para Rudalevige (2002), os custos de transação na relação entre o Presidente e os ministros não podem ser traduzidos em dollars and cents, mas podem ser identificados como diretamente associados à informação. Os ministros representam a divisão do trabalho e o controle de informação específica sobre determinado tema. Contudo, eles podem ter interesses próprios que diferem dos interesses do Presidente. Dessa forma, este tem que escolher a opção que maximize informação confiável sobre o projeto em questão. Para avaliar a "confiabilidade" da informação, para usar os termos de Rudalevige (2002), aqui são analisadas quatro características específicas: as preferências dos atores; o número de atores envolvidos na decisão; a institucionalização do órgão de apoio direto ao Presidente e a força legislativa dos atores no processo decisório.

Figura 1

Processo de Produção Legislativa no Executivo

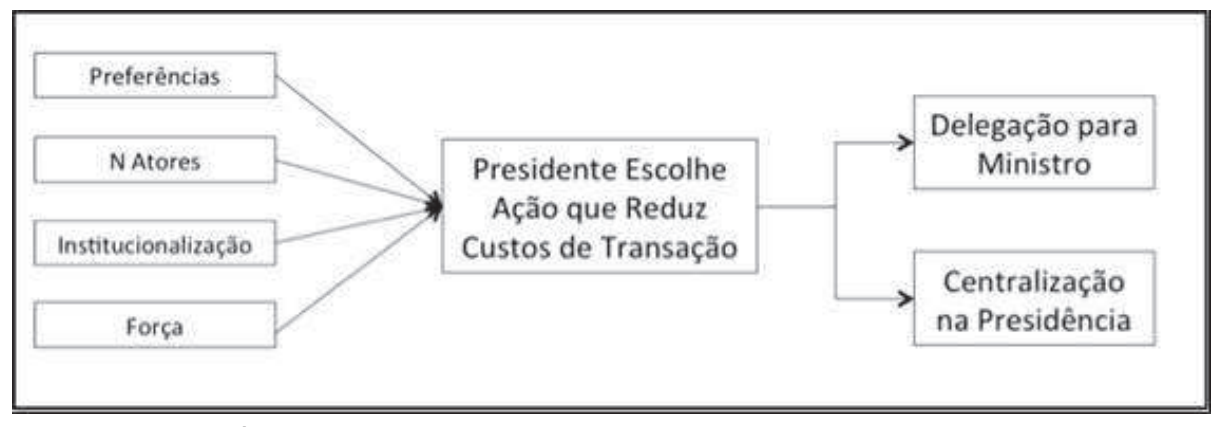

Fonte: Elaboração própria.

Compreendidos os custos associados às duas opções, por que o Presidente escolhe delegar para os ministros em alguns casos, mas, em outros, é observada a centralização na Presidência? Com base no argumento clássico, o Presidente escolhe a opção que reduz os custos de transação. Nesse sentido, é esperado que o Presidente centralize quando a distância de preferências com o ministro seja maior, indicando a baixa confiabilidade das informações advindas dos ministérios. Quando o número de atores aumentar é esperada a centralização, tendo em vista que mais partidos numa decisão tendem a aumentar os custos de obtenção de um acordo que todos eles prefiram ao status quo, sendo necessária a coordenação. A institucionalização do órgão de apoio direto ao Presidente diminui os custos de centralização, já que estabelece uma fonte de informações confiáveis independente dos ministérios ${ }^{4}$. Por último, com base no argumento de que os ministros representam apoio político ao Presidente no

\footnotetext{
4 Segundo a definição clássica de Polsby, uma organização pode ser considerada institucionalizada quando: "1) It is relatively well-bounded, that is to say, differentiated from its environment. Its members are easily identifiable, it is relatively difficult to become a member, and its leaders are recruited principally from within the organization. 2) The organization is relatively complex, that is, its functions are internally separated on some regular and explicit basis, its parts are not wholly interchangeable, and for at least some important purposes, its parts are interdependent. There is a division of labor in which roles are specified, and there are widely shared expectations about the performance of roles. There are regularized patterns of recruitment to roles and of movement from role to role. 3) Finally, the organization tends to use universalistic rather than particularistic criteria, and automatic rather than discretionary methods of conducting its internal business. Precedents and rules are followed; merit systems replace favoritism and nepotism; and impersonal codes supplant personal preferences as prescriptions for behavior" (POLSBY, 1968, p. 145).
} 
Legislativo, o aumento na força legislativa do partido do ministro diminuiria a centralização, já que, nesse caso, o Presidente perderia em apoio. A próxima seção dedica-se ao teste empírico de tais argumentos.

\section{Presidência e Ministérios na produção legislativa do Executivo}

Para compreender a escolha do Presidente quanto às duas opções de produção legislativa, foram analisadas as iniciativas legislativas do Poder Executivo no período de 1995 a 2010, compreendendo os dois mandatos de Fernando Henrique Cardoso e de Luiz Inácio Lula da Silva. As iniciativas legislativas incluídas são as Medidas Provisórias (MPV), os Projetos de Lei Ordinária (PL), os Projetos de Lei Complementar (PLP) e os Projetos de Emenda Constitucional (PEC). A lista de todas as iniciativas legislativas submetidas ao Congresso foi disponibilizada pelo Ministério da Justiça.

A análise baseia-se na autoria dos projetos para identificar os casos em que a iniciativa legislativa é mais ou menos centralizada. Para tanto, foi construído um banco de dados original com base nas "exposições de motivos", documento interno ao Executivo que acompanha as iniciativas legislativas. Em tal documento, são registradas as justificativas dos ministros (sejam dos Ministérios ou da Presidência) para o projeto em questão e, a partir dele, é possível identificar por quais ministros o projeto foi construído. As exposições de motivos foram coletadas do sistema da Casa Civil e da Câmara dos Deputados. Os casos em que a exposição de motivos não estava disponibilizada nos dois sistemas foram solicitados ao Ministério da Justiça, que mantém um acervo do envio e da tramitação das propostas de interesse do Executivo no Legislativo.

Um total de 1.715 iniciativas do Executivo foram analisadas, dentre 823 PLs, 784 MPVs, 54 PECs e 54 PLPs. Tais iniciativas incluem projetos submetidos ao Congresso, aprovados, rejeitados ou ainda em tramitação. As iniciativas legislativas que se referem a créditos adicionais (148 iniciativas) foram retiradas da amostra por se tratar de um tema específico ao Ministério do Planejamento, que apenas inflaria a participação desse Ministério na produção legislativa do Poder Executivo. Foram excluídas ainda as iniciativas de autoria de ministérios "militares": Marinha, Aeronáutica, Exército e Estado Maior (43 projetos).

Do total de iniciativas, não foi possível identificar a autoria da iniciativa através da exposição de motivos em 187 casos. Vale salientar que nenhum aspecto sistemático foi encontrado que pudesse gerar viés na análise, já que esse número de missing se deve a casos onde o nome do ministro aparece ilegível ou a exposição não é assinada.

Para um primeiro olhar sobre a autoria dos projetos foi criada uma escala e 0 a 5 , na qual 0 é a opção menos centralizada de formulação legislativa e 5 a opção mais centralizada à disposição do Presidente: zero (0) é atribuído quando o projeto é construído por ministros vinculados aos demais partidos da coalizão, 1 quando é realizado conjuntamente por ministros da coalizão e ministros do partido do Presidente, 2 para projetos construídos por ministros do partido do Presidente, 3 para projetos construídos por partidos da coalizão em conjunto com a Presidência, 4 para projetos conjuntos da Presidência e membros do partido do presidente, e, por último, 5 para projetos construídos pela 
Presidência ${ }^{5}$. O Gráfico 1 apresenta os resultados iniciais quanto à autoria dos projetos com base na média de projetos por ano:

Gráfico 1

Grau de Centralização das Iniciativas Legislativas do Executivo (1995-2010)

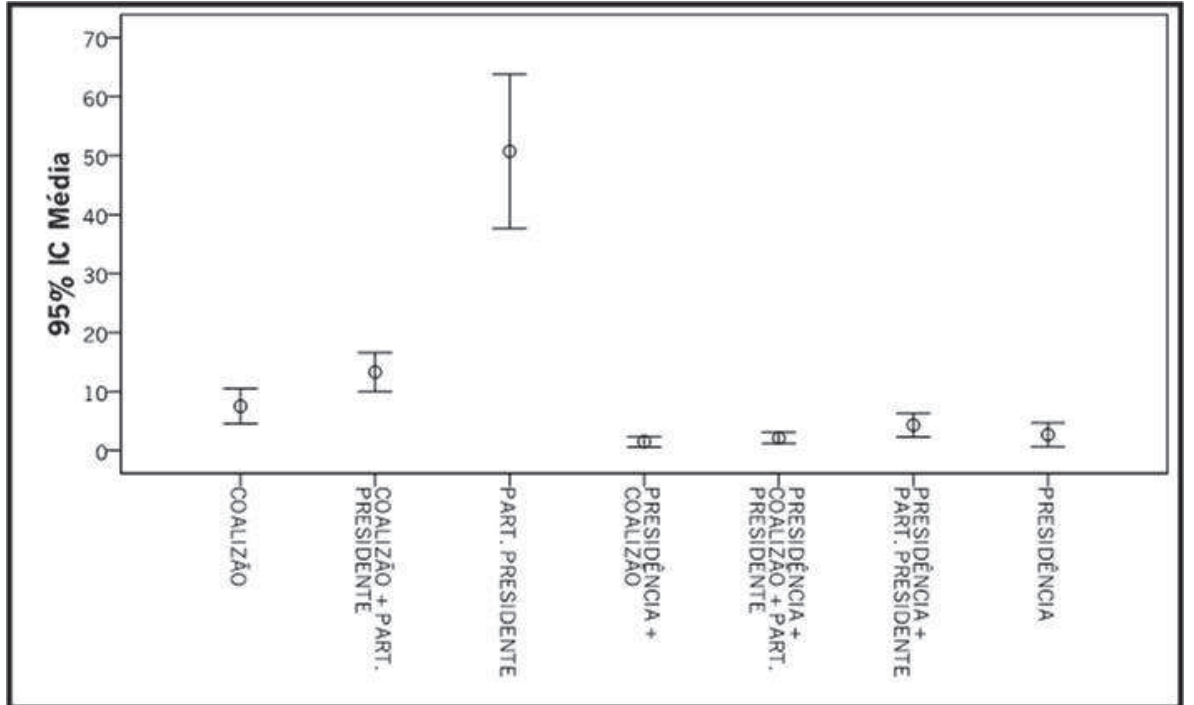

Fonte: Elaboração própria com base em dados da Casa Civil, Câmara dos Deputados e Ministério da Justiça.

O Gráfico 1 compara as médias e o intervalo de confiança para as opções de produção de iniciativas legislativas no Poder Executivo. Como pode ser visto, a grande maioria dos projetos tem sua iniciativa nos Ministérios, evidenciando a importância dos ministros no processo de produção legislativa no Poder Executivo. Adicionalmente, nota-se que a participação dos ministros membros da coalizão é ainda baixa quando comparada com a participação dos ministros membros do partido do Presidente. Neste sentido, apesar de haver grande número de ministros e de partidos diferentes integrando o governo, o Presidente ainda busca mais o apoio do seu próprio partido para a formulação da agenda legislativa. O papel da Presidência se dá coordenando projetos com membros não só dos demais partidos da coalizão como também do partido do Presidente. Além disso, a Presidência aparece como autora de projetos sem a participação de Ministérios, mas, comparando à participação dos Ministérios na produção legislativa, a atuação da Presidência é ainda bem restrita. É, contudo, uma opção viável para o Presidente.

\footnotetext{
${ }^{5}$ Os ministros sem filiação partidária foram considerados como membros do partido do Presidente.
} 


\section{Gráfico 2}

Grau de Centralização: comparando presidentes (1995-2010)

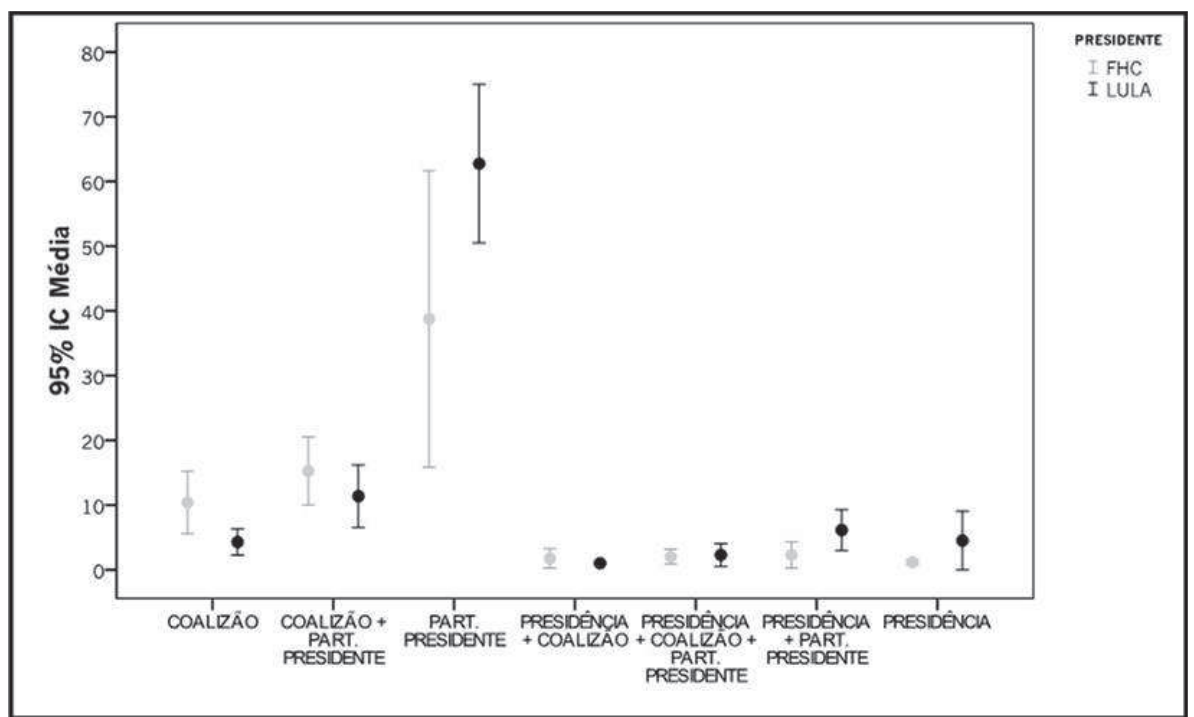

Fonte: Elaboração própria com base em dados da Casa Civil, Câmara dos Deputados e Ministério da Justiça.

O Gráfico 2 compara o grau de centralização na produção legislativa nos governos FHC e Lula. Observando-se as médias de iniciativas por ano, é notável a diminuição na participação dos ministros membros da coalizão no governo Lula em comparação à participação desses ministros no governo FHC. Projetos de autoria de membros da coalizão e também em conjunto com Ministros do partido do Presidente diminuíram, ao passo que a participação dos Ministros do partido do Presidente aumentou no governo Lula. Adicionalmente, a participação da Presidência na produção legislativa aumentou no governo Lula, em comparação aos governos FHC. Contudo, a análise dos intervalos de confiança não permite afirmar uma diferença significativa entre os Presidentes nesse estágio descritivo da análise.

Uma ressalva que pode ser feita à expressiva participação do partido do Presidente é observar que a distribuição de Ministérios no presidencialismo de coalizão brasileiro tem cada vez mais beneficiado o partido do Presidente. A taxa de coalescência ${ }^{6}$ não é alta e a participação do partido do Presidente varia do mínimo de $32,7 \%$ das cadeiras no gabinete no segundo governo de FHC ao máximo de $64,5 \%$ no primeiro governo Lula 7 . Dessa forma, a maior participação dos Ministros do partido do Presidente pode ser diretamente vinculada à distribuição de cargos no momento de formação do governo de coalizão.

Até o momento, a participação dos Ministérios e da Presidência foi apresentada para mostrar o "grau" de centralização da produção legislativa, evidenciando o papel dos partidos membros da coalizão, do partido do Presidente e da Presidência da República. Nota-se a forte participação dos ministros membros do partido do Presidente e a participação menos expressiva dos partidos da coalizão, mesmo considerando o aumento do número de partidos nas coalizões ao longo do tempo. Adicionalmente, pode-

\footnotetext{
${ }^{6}$ Para maiores detalhes sobre a taxa de coalescência e seus efeitos ver Amorim Neto (2006)

7 Banco de Dados Legislativos do Cebrap.
} 
se notar que a participação da Presidência é relativamente circunstancial quando se compara o número de projetos com sua participação ao número de projetos dos Ministérios, mesmo não havendo bases para afirmar se tal participação é baixa ou alta, já que estudos comparados ainda estão em estágio inicial.

Tendo em vista que o foco do artigo é a transação e o objetivo é entender quando o Presidente decide centralizar a produção legislativa na Presidência, a codificação da autoria dos projetos foi transformada de forma a apresentar duas opções: Ministérios ou Presidência. Projetos de ministros da coalizão, do partido do Presidente ou mistos formam uma categoria e projetos com participação ou de autoria exclusiva da Presidência outra categoria. O Gráfico 3 apresenta a participação dos Ministérios e da Presidência na formulação da agenda legislativa do Executivo:

\section{Gráfico 3}

Ministérios e Presidência na Produção Legislativa (1995-2010)

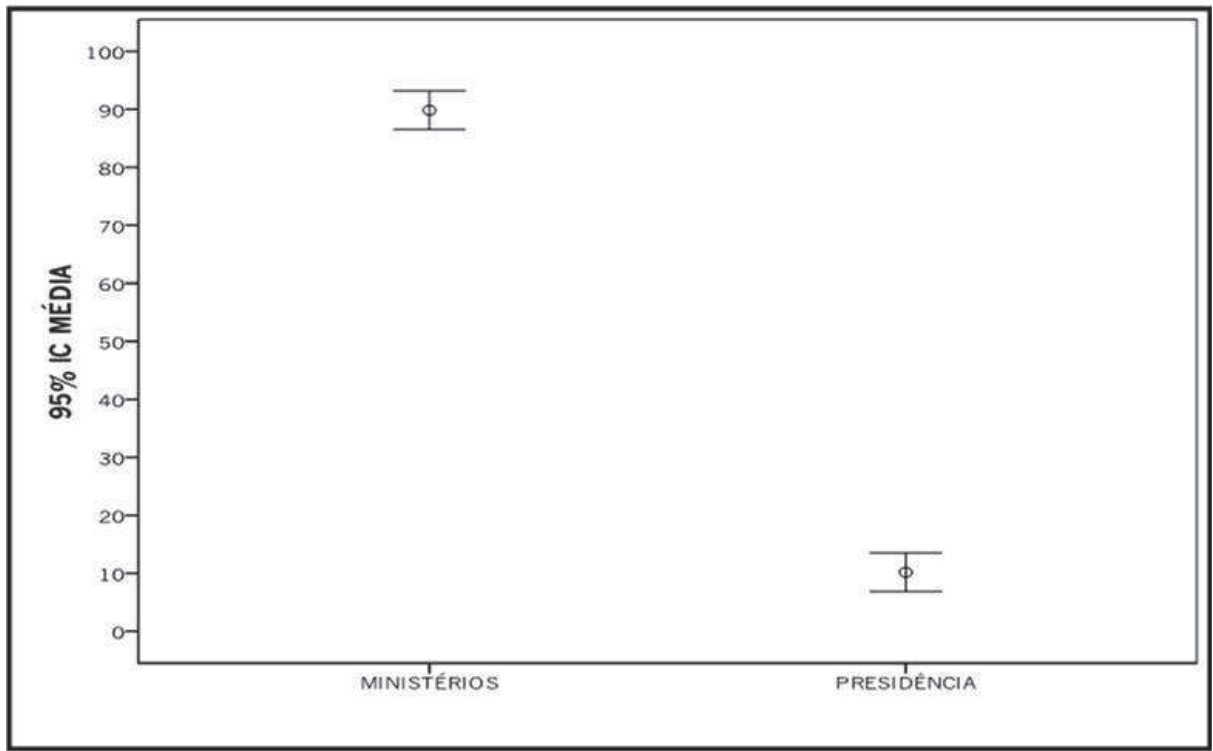

Fonte: Elaboração própria com base em dados da Casa Civil, Câmara dos Deputados e Ministério da Justiça.

O Gráfico 3 compara a participação da Presidência na produção legislativa do Executivo. Como pode ser visto, a grande maioria dos projetos, cerca de 90\%, têm sua origem nos Ministérios, evidenciando a forte descentralização da produção legislativa no Executivo e o importante papel dos ministros. Contudo, a Presidência também aparece como ator relevante na produção legislativa do Executivo. O Gráfico 4 compara os governos FHC e Lula: 


\section{Gráfico 4}

Governos e Formulação da Agenda Legislativa (1995-2010)

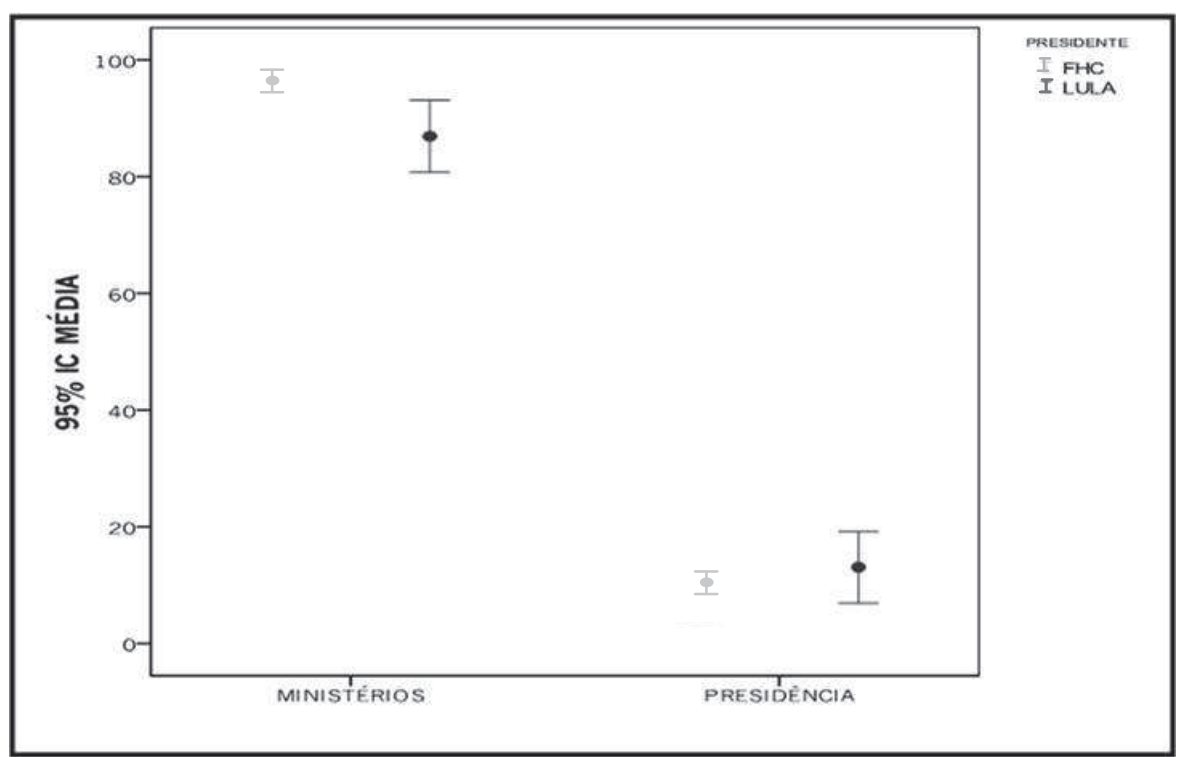

Fonte: Elaboração própria com base em dados da Casa Civil, Câmara dos Deputados e Ministério da Justiça.

Comparando-se os governos FHC e Lula na distribuição de iniciativas legislativas entre os Ministérios e a Presidência, nota-se que a participação dos Ministérios diminuiu e a atuação da Presidência aumentou no governo Lula. A média de centralização é maior nos governos Lula. Contudo, há maior variação ao longo dos anos de governo Lula, de modo que a diferença não é significativa.

O Gráfico 5 apresenta a evolução da atuação da Presidência ao longo do período aqui analisado: 
Gráfico 5

Evolução da Centralização na Presidência (1995-2010)

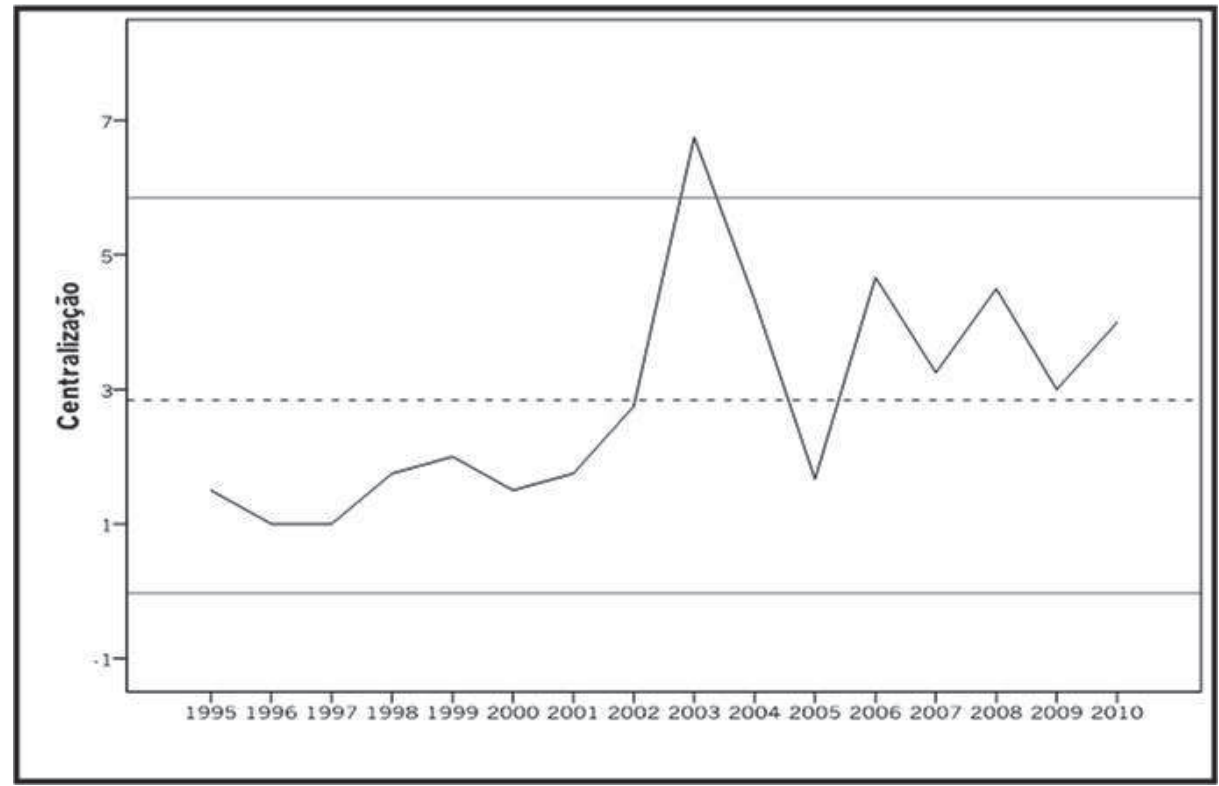

Fonte: Elaboração própria com base em dados da Casa Civil, Câmara dos Deputados e Ministério da Justiça.

Com base na autoria de iniciativas legislativas, pode-se notar que a atuação da Presidência era bastante baixa no início do governo FHC, aumentando ao longo do seu mandato, até atingir o pico durante o primeiro ano do governo Lula. Após esse aumento inicial, a atuação da Presidência cai até abaixo da média em 2005, mas depois volta a subir, mantendo-se acima da média durante todo o resto do governo Lula. Uma tentativa de interpretação para esse padrão interessante do início do governo Lula pode estar na expectativa no início do governo de estabelecer na Casa Civil forte controle sobre as decisões do governo, contando com a chefia de José Dirceu. A queda da centralização coincide com a crise no governo Lula e o escândalo do "mensalão", quando o chefe da Casa Civil foi diretamente implicado.

A análise de tais resultados iniciais já mostra o papel predominante dos Ministérios no controle de informação e na tomada de decisão acerca das iniciativas legislativas do Poder Executivo. Nesse sentido, para usar os termos da literatura especializada, as trocas de mercado parecem ser mais vantajosas na maioria dos casos do que a integração da produção. Os ministros controlam informação especializada no tema em questão, controlam também a burocracia responsável pela área e representam o apoio do seu partido à agenda legislativa do Executivo no Congresso. Toda uma literatura sobre governos de coalizão em sistemas parlamentaristas, com base em Laver e Shepsle (1990), indica a predominância dos Ministérios no controle da produção legislativa da área sob sua responsabilidade.

Contudo, um número não desprezível de iniciativas legislativas teve a sua centralização na Presidência, o que, como visto na seção anterior, apresenta custos. Perde-se em expertise e em apoio legislativo. Por que, então, o Presidente decide centralizar a produção de alguns projetos? Quando a 
opção pela produção legislativa nos Ministérios deixa de ser viável? Em outras palavras, quais fatores influenciam a decisão do Presidente de deslocar a tomada de decisão dos Ministérios para a Presidência?

Apesar de a centralização ser um fenômeno relativamente raro, ele merece devida explicação. Esse é o objetivo da próxima seção.

\section{Estimando os Fatores Explicativos da Centralização: uma análise exploratória}

O que explica a decisão do Presidente de centralizar o processo decisório de produção legislativa na Presidência?

A natureza exploratória desta análise e o escasso desenvolvimento de pesquisas empíricas sobre o tema no Brasil não permitem resultados conclusivos sobre o assunto. No entanto, o objetivo desta seção é avaliar as condições sob as quais o Presidente escolhe centralizar as iniciativas legislativas, de acordo com as quatro hipóteses derivadas da abordagem da economia dos custos de transação, como visto na primeira seção.

Na sequência, são apresentadas as variáveis independentes, bem como o método de estimação para a análise aqui proposta, seguidos pelos resultados e também pelas lacunas na pesquisa aqui apresentada.

Mensurando a Variável Dependente

O fenômeno de interesse é a centralização da produção legislativa. Dessa forma, a unidade de análise é a transação e o foco as características de cada iniciativa legislativa especificamente. Focalizar cada iniciativa separadamente permite descer o nível da análise até cada decisão específica, incluindo variação entre projetos da mesma coalizão ou do mesmo Ministério. Nesse sentido, trata-se de uma medida desagregada e a variável dependente é uma variável de resposta qualitativa binária, assumindo o valor 0 quando o projeto tem a autoria dos ministros e 1 quando tem a participação da Presidência.

Mensurando as Variáveis Independentes

\section{Distância Ideológica}

As preferências dos atores são o ponto de partida para entender as escolhas que fazem. Assim, a distância de preferências entre o Presidente e os ministros busca captar a confiabilidade das informações advindas do Ministério. Espera-se que essas informações sejam mais confiáveis quando os Ministérios compartilham dos mesmos interesses do Presidente.

Como proxy para as preferências dos atores, foi usada a posição ideológica do seu partido. No caso dos ministros, foi usada a posição ideológica do partido ao qual é filiado e, para o Presidente, foi usada a posição ideológica do seu partido. O uso da ideologia do partido como proxy para preferências não é o ideal, pois os atores podem ter preferências divergentes de seu partido e também porque a posição ideológica não permite compreender as preferências dos atores quanto a matérias específicas. Contudo, permite visualizar, em linhas gerais, os pontos de acordo e conflito entre os atores e por isso a uso neste artigo.

A mensuração da distância ideológica foi feita com base nos dados de Zucco e Lauderdale (2011). Esta é uma medida especialmente boa porque usa ideal point estimation com a ajuda de surveys 
BATISTA, M. O poder no Executivo: uma análise do papel da Presidência e dos Ministérios...

para identificar uma dimensão ideológica no comportamento dos legisladores ${ }^{8}$. Além disso, resulta em uma medida contínua, permitindo a visualização espacial das coalizões formadas no período ${ }^{9}$. Com base nesses dados, foi calculada a distância entre a posição do Presidente e a posição do(s) ministro(s) responsável(eis) pelo projeto. Como, em muitos casos, mais de um ministro é responsável pela área em questão, foi utilizado o somatório das distâncias com relação à posição do Presidente, como mostrado pela fórmula:

$$
D I P M_{J}=\sum \sqrt{\left(P p_{I J}-P m_{I J}\right)^{2}}
$$

A distância ideológica entre o Presidente e o ministro é calculada com base na distância euclidiana para espaços unidimensionais, onde se subtrai $P p$ a posição ideológica do presidente $I$ na matéria $I$ da $P m$ posição ideológica do ministro $I$ na matéria $I$, corrigindo pelo efeito dos números negativos.

Para os casos em que a Presidência foi o único autor da matéria foi feita uma classificação quanto ao(s) ministério(s) responsável(eis) com base na ementa das matérias. Um exemplo de tal classificação é a chamada "Lei Geral das Agências Reguladoras", projeto da Casa Civil que classifiquei como ministérios responsáveis o Ministério do Planejamento e os ministérios aos quais as agências regulatórias são vinculadas (Minas e Energia, Comunicações, Defesa, Cultura, Meio Ambiente, Saúde, Transportes). Desta forma, é possível identificar a distância ideológica entre o Presidente e os ministros, mesmo no caso de projeto de autoria da Presidência ${ }^{10}$.

Dito isto, espera-se que o aumento na distância ideológica entre o Presidente e os ministros aumente a chance de centralização, devido ao conflito de interesses e baixa confiabilidade das informações dos ministros. A hipótese correspondente $(\mathrm{H} 1)$ é que:

H1: quanto maior a distância ideológica entre o Presidente e o ministro, maior a probabilidade de centralização $(+)$.

\section{Número de Atores}

A variável "número de atores" tem por base a literatura sobre custos de transação, que indica que a maior quantidade de interesses envolvidos tende a aumentar os custos de obtenção de um acordo que todos prefiram ao status quo, sendo necessária a coordenação. A mensuração foi feita a partir do número de ministros autores do projeto. Com base nisso, a segunda hipótese (H2) é a seguinte:

H2: quanto maior o número de atores, maior a probabilidade de centralização (+).

8 O estudo também identificou outra dimensão a orientar o comportamento dos legisladores que pode ser chamada de "governo oposição".

9 Os dados estão disponíveis em: <http://dvn.iq.harvard.edu/dvn/dv/zucco>.

10 Usar este tipo de classificação não é o ideal tendo em vista que envolve subjetividade. Contudo, foi a única opção encontrada para resolver o viés nos resultados se a posição ideológica do ministro da Presidência fosse utilizada, já que a distância entre o Presidente e a Presidência é sempre 0. Tal classificação foi utilizada em 35 casos e tem por base o trabalho de Rudalevige (2002). 


\section{Institucionalização do Apoio Direto}

Espera-se que a institucionalização do órgão de apoio direto ao Presidente diminua os custos de centralização, já que estabelece uma fonte de informações confiáveis independente dos Ministérios. Com uma burocracia desenvolvida, leal e responsiva apenas ao Presidente, este tem incentivos para substituir os Ministérios pela Presidência na produção legislativa, já que teria uma fonte de informações confiáveis e independente dos Ministérios.

Institucionalização é um conceito amplo que pode envolver aumento de pessoal, da estrutura e a diferenciação nos órgãos que compõem a Presidência. No presente artigo, incluo apenas a quantidade de funcionários da Casa Civil, órgão de apoio e assessoramento direto ao Presidente da República na área legislativa. Os dados foram obtidos através de solicitação à própria Casa Civil. O anexo apresenta a evolução do número de funcionários da Casa Civil no período analisado. Com relação à institucionalização do apoio direto, a $3^{\mathrm{a}}$ hipótese $(\mathrm{H} 3)$ diz que:

H3: quanto maior o número de funcionários da Casa Civil, maior a probabilidade de centralização (+).

\section{Força Legislativa dos Partidos da Coalizão}

Por último, com base no argumento de que o Presidente troca posições no gabinete por apoio no Legislativo, a força legislativa desses partidos torna-se uma variável relevante. Os ministros representam apoio político e o aumento na força legislativa do partido do ministro diminuiria a centralização, já que nesse caso o Presidente perderia em apoio.

A mensuração da força legislativa do ministro foi feita com base na porcentagem de cadeiras do partido na Câmara dos Deputados. Informações do Banco de dados legislativos do Cebrap e do site da Câmara dos Deputados foram utilizadas. Para o caso de matérias com mais de um ministro foi utilizada a média. Para as matérias de origem na Presidência, a mesma classificação das matérias para a variável distância ideológica foi utilizada, no sentido de calcular a força do partido do ministro responsável pela área. Assim, a $4^{a}$ hipótese $(\mathrm{H} 4)$ deste artigo é que:

H4: quanto maior a força legislativa do partido do ministro, menor a probabilidade de centralização (-).

\section{Variáveis de Controle}

Além destas quatro variáveis de interesse, foram incluídas as seguintes variáveis de controle:

\section{Presidente}

Variável dummy para o Presidente Lula. Espera-se que seus projetos apresentem maior probabilidade de centralização (+).

$\underline{\text { Ano }}$

Esta variável busca testar o argumento de Moe (1985) acerca da "centralização linear", segundo o qual a centralização deveria aumentar linearmente tendo em vista o aumento nas demandas sobre o governo. Para manter controle do governo o Presidente centralizaria. Tal variável é calculada como o número de anos entre a proposição da iniciativa legislativa e o ano da redemocratização 1985. $(+)$. 
BATISTA, M. O poder no Executivo: uma análise do papel da Presidência e dos Ministérios...

Área da Matéria

Variáveis dummy para matérias administrativas, políticas e sociais. Espera-se que matérias administrativas apresentem maior probabilidade de centralização, já que envolvem reorganização do governo e as informações específicas dos Ministérios podem ser insuficientes ou enviesadas (RUDALEVIGE, 2002). Foi usada a classificação das matérias do Banco de dados legislativos do Cebrap (+).

\section{Tipo da Matéria}

Variáveis dummy para o tipo do projeto: medida provisória, projeto de lei ordinária, projeto de emenda constitucional e projeto de lei complementar. Espera-se que medidas provisórias apresentem maior probabilidade de centralização, já que se trata de matérias de urgência $(+)^{11}$.

\section{Ciclo Eleitoral}

Variáveis dummy para o primeiro e o último ano do mandato. Espera-se que o primeiro e o último anos do mandato aumentem a probabilidade de centralização. O primeiro por se tratar de um momento de adaptação do governo e o último pela proximidade da eleição, situação na qual alguns ministros podem estar envolvidos em disputas eleitorais (+).

\section{Método e Resultados}

O estudo se propõe a analisar os fatores que explicam a decisão do Presidente de centralizar a produção legislativa na Presidência. Por se tratar de uma variável binária, um modelo logístico mostra-se apropriado ${ }^{12}$. Contudo, como visto anteriormente, a centralização pode ser considerada um "evento raro", de modo que o modelo logístico tradicional implica em viés na análise. Isto é, no modelo de regressão logística onde se observa poucos 1 (evento) e muitos 0 (não-evento), a variável mostra-se difícil de prever e explicar porque o modelo sistematicamente superestima a probabilidade de 0 e subestima a probabilidade de 1 (KING e ZENG, 2001).

King e Zeng (2001) propõem um modelo logístico corrigido para esse tipo de variável que trabalha com fenômenos como guerras ou vetos presidenciais. O logit eventos raros (Relogit) corrige o viés do modelo logístico tradicional ao diminuir o mean square error e assim aumenta a probabilidade do evento (KING e ZENG, 2001). Os autores ainda desenvolveram o software para implementação do método que pode ser usado no Stata ${ }^{13}$. Os resultados para a centralização da produção legislativa durante o período de 1995 a 2010 são apresentados na Tabela 1:

\footnotetext{
${ }_{11}^{11}$ Agradeço a Carlos Pereira por chamar a atenção para este ponto.

12 Modelos logísticos podem "esconder" informação, já que só permitem duas opções, 0 ou 1, e estimam a probabilidade de sucesso. No entanto, o modelo logístico é o mais apropriado para responder a questão aqui estabelecida sobre os fatores que influenciam a decisão específica do Presidente quanto à centralização de iniciativas legislativas. Uma alternativa seria o uso de modelos de contagem, como o binomial negativo. Contudo, para o uso de tal modelo seria necessária alguma forma de agregação da variável dependente, o que não se adequaria com a forma que a questão de pesquisa foi aqui estabelecida. Agradeço ao parecerista anônimo por chamar a atenção para este ponto.

${ }^{13}$ Disponível para download em: <http://Gking. Harvard.Edu>.
} 
OPINIÃO PÚBLICA, Campinas, vol. 19, n², novembro, 2013, p. 449-772

Tabela 1

Relogit - Centralização da Produção Legislativa na Presidência (1995-2010)

\begin{tabular}{|l|c|c|}
\hline Variável & VD $=$ Centralização & VD $=$ Centralização CC \\
\hline Constante & $.4 .16^{* * *}(.76)$ & $.4 .47^{* * *}(.88)$ \\
\hline Distância Ideológica & $.22^{* * *}(.11)$ & $.25^{* * *}(.08)$ \\
\hline$N^{\circ}$ Atores & $.20^{* * *}(.07)$ & $.19^{* *}(.08)$ \\
\hline Casa Civil & $.00^{* *}(.00)$ & $.00^{* * *}(.00)$ \\
\hline Força Legislatura & $.05(.03)$ & $.07^{*}(.04)$ \\
\hline Lula & $1.35^{* * *}(.42)$ & $1.88^{* * *}(.50)$ \\
\hline Ano & $.16^{* * *}(.05)$ & $.28^{* * *}(.06)$ \\
\hline Administrativa & $.79^{* * *}(.27)$ & $.84^{* * *}(.30)$ \\
\hline Política & $1.91^{* * *}(.54)$ & $2.23^{* * *}(.60)$ \\
\hline Social & $.51^{* *}(.26)$ & $.09(.31)$ \\
\hline MPV & $.46^{* *}(.21)$ & $.92^{* * *}(.26)$ \\
\hline PEC & $.85(.72)$ & $1.22(.77)$ \\
\hline PLP & $.25(.52)$ & $.81(.53)$ \\
\hline 1 ano & $.48^{* *}(.23)$ & $.45^{*}(.27)$ \\
\hline 4 ano & $.47^{*}(.26)$ & $.61^{* *}(.31)$ \\
\hline Planejamento & $.16(.21)$ & $.32(.25)$ \\
\hline N & 1.242 & 1242 \\
\hline
\end{tabular}

Coeficientes reportados

Erro-padrão robusto entre parênteses.

*** Significativo no nível 0.01

** Significativo no nível 0.05

* Significativo no nível 0.10

O modelo Relogit não oferece um teste de "goodness of fit" similar ao $\mathrm{R}^{2}$ para o modelo de Mínimos Quadrados Ordinários. Normalmente, calculam-se valores "pseudo- $R^{2 " ~ n o ~ L o g i t, ~ m a s ~ t a l ~}$ estratégia é fortemente desaconselhada pelo próprio Gary King (2003). Nesse sentido, a interpretação dos resultados se dá com base na direção, na magnitude e na significância dos coeficientes.

Como forma de testar a robustez dos resultados, foram estimados dois modelos com uma modificação na variável dependente. No primeiro, a variável dependente á a centralização medida como a autoria de todos os órgãos da Presidência da República, incluindo a Casa Civil, as Secretarias Especiais e os demais órgãos. No segundo modelo, a centralização é medida de forma mais restrita, incluindo apenas a autoria da Casa Civil. A inclusão dessa modificação na variável dependente tem por justificativa a centralidade da Casa Civil como órgão de supervisão e monitoramento da produção legislativa do Poder Executivo, sendo uma de suas funções a avaliação jurídica e de mérito do conteúdo das iniciativas legislativas do Executivo ${ }^{14}$. Adicionalmente, considera também a possibilidade da centralização aumentar durante o governo Lula simplesmente pelo número de órgãos, principalmente o de Secretarias Especiais, ter aumentado durante esse governo.

${ }^{14}$ Ver Lei $n^{\circ} 10.683$. 
BATISTA, M. O poder no Executivo: uma análise do papel da Presidência e dos Ministérios...

Nos dois modelos, a variável que representa a distância ideológica entre o Presidente e o ministro apresenta o sinal positivo esperado e é significativa. Isto é, quanto maior a distância de preferências entre o Presidente e o ministro, maior a probabilidade de centralização. O número de ministros envolvidos na matéria apresenta o sinal esperado, isto é, aumenta a probabilidade de centralização, e apresenta forte significância estatística nos dois modelos. Isto mostra que o grande número de atores envolvidos de fato aumenta os custos para a tomada de decisão e o estabelecimento de um acordo, sendo necessária a ação da Presidência.

O aumento de pessoal da Casa Civil também está associado positivamente ao aumento da centralização, resultado fortemente significativo nos dois modelos. Pode-se assim entender que o fortalecimento do órgão de apoio direto ao Presidente representa uma fonte alternativa de informação que não o Ministério. Por último, a força legislativa do partido do ministro não apresentou resultados consistentes, aparecendo com o sinal contrário ao esperado. Contudo, tal resultado não é significativo estatisticamente. Sua interpretação literal indicaria que o aumento da porcentagem média de cadeiras dos ministros na Câmara aumentaria a probabilidade de centralização. Não distante, de acordo com o argumento de que a inclusão como ministros dos representantes dos partidos da coalizão no governo ocorreria em troca de apoio no Legislativo, o aumento na força de tais partidos deveria diminuir a probabilidade de centralização. Nesse sentido, a força legislativa do partido do ministro não se traduz em participação na agenda legislativa do Poder Executivo. Este é um resultado que merece maior atenção e aprofundamento futuro. Porém, é possível supor que, talvez, a força dos partidos não se traduza em maior participação na agenda legislativa, seja por decisão do Presidente de controlar as decisões do governo, seja porque a influência dos partidos seja direcionada a outras decisões que não a agenda legislativa.

Com relação às variáveis de controle apresentadas no segundo modelo, os principais resultados são de que as matérias do governo Lula, de fato, apresentam maior probabilidade de centralização. Nesse sentido, mesmo controlando pelo fortalecimento da Casa Civil, o governo Lula mostrou-se mais centralizador. Desta forma, para além da institucionalização, estilos de liderança podem de fato afetar os resultados, como argumenta Neustadt (1961).

O argumento da centralização linear não só não se sustenta como aparece como evidência contrária. Controlando pelas demais variáveis apresenta um efeito negativo. Nesse sentido, o argumento de Rudalevige (2002), que aponta a centralização como algo contingente às características da matéria e não uma evolução estrutural, mostra-se mais adequado. Ainda de acordo com o argumento de Rudalevige, os resultados mostram que matérias administrativas de fato apresentam maior probabilidade de centralização, indicando a baixa confiabilidade e relevância das informações dos Ministérios quando reorganizações governamentais estão em discussão. Adicionalmente, matérias políticas também apresentam maior probabilidade de centralização. As matérias sociais aumentam a probabilidade de centralização significativamente apenas no primeiro modelo.

Quanto às variáveis sobre o tipo da matéria, foram incluídas dummies e os projetos de lei são a categoria de referência. Como esperado, as medidas provisórias apresentam maior probabilidade de centralização. Contudo, PECs e PLPs não apresentam diferença significativa. O primeiro e o último ano 
de mandato também representam aumento na probabilidade de centralização, identificando o efeito da fase de adaptação no primeiro ano e de partidos envolvidos em eleições no último ano.

Os coeficientes do modelo de regressão logística apresentados na Tabela 1 não possuem interpretação substantiva, sendo necessário um procedimento adicional para entender a magnitude do efeito das variáveis explicativas analisadas através de probabilididades ${ }^{15}$. A Tabela 2 apresenta as probabilidades preditas e o intervalo de confiança para as variáveis dicotômicas que tiveram significância nos dois modelos. A quantidade foi calculada mantendo as demais variáveis contínuas na média e as variáveis dicotômicas em 0 .

Tabela 2

Probabilidade de Centralização

Variáveis Dicotômicas Modelo Relogit

\begin{tabular}{|l|c|c|}
\hline Variável & $\operatorname{Pr}$ (Centralização) & I.C. $\mathbf{9 5 \%}$ \\
\hline Lula & 0.07 & 0.03 a 0.12 \\
\hline Administrativa & 0.04 & 0.02 a 0.08 \\
\hline Política & 0.11 & 0.04 a 0.25 \\
\hline MPV & 0.03 & 0.01 a .06 \\
\hline $1^{\circ}$ Ano & 0.03 & 0.01 a .06 \\
\hline $4^{\circ}$ Ano & 0.03 & 0.01 a .05 \\
\hline Fonte: elaboração própria.
\end{tabular}

$\mathrm{Na}$ Tabela 2, vemos a probabilidade de centralização quando a variável independente assume o valor 1 e as demais são mantidas constantes. A probabilidade de centralização é de 0.07 quando a iniciativa legislativa tem sua formulação durante o governo Lula; é de 0.04 quando a matéria é administrativa; 0.11 quando envolve assunto político e de 0.03 tanto quando a iniciativa é uma medida provisória como quando o Presidente está no seu primeiro ou quarto ano de mandato. Os Gráficos 6a, 6b e 6c apresentam a probabilidade de centralização para as variáveis contínuas:

\footnotetext{
15 Probabilidades podem ser obtidas para o modelo Relogit no Stata através dos comandos "setx" e "relogitq".
} 
BATISTA, M. O poder no Executivo: uma análise do papel da Presidência e dos Ministérios...

\section{Gráfico 6}

Probabilidade de Centralização - Modelo Relogit

6a) Distância Ideológica

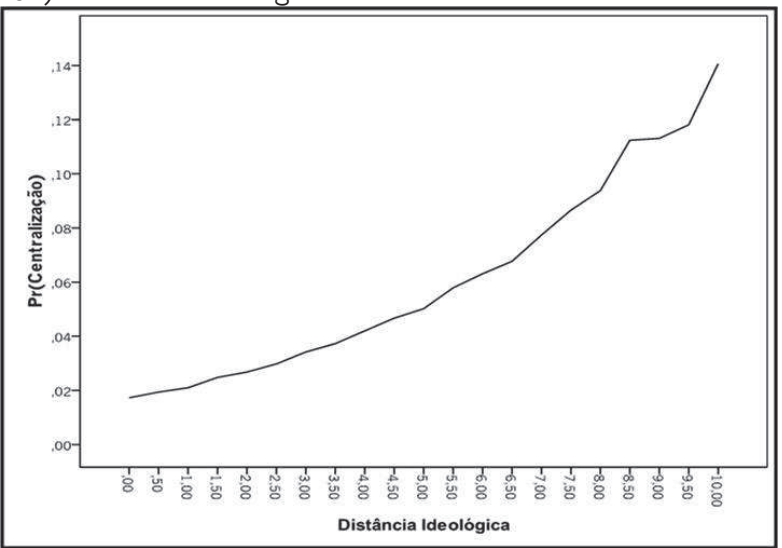

6b) Número de pessoal da Casa Civil

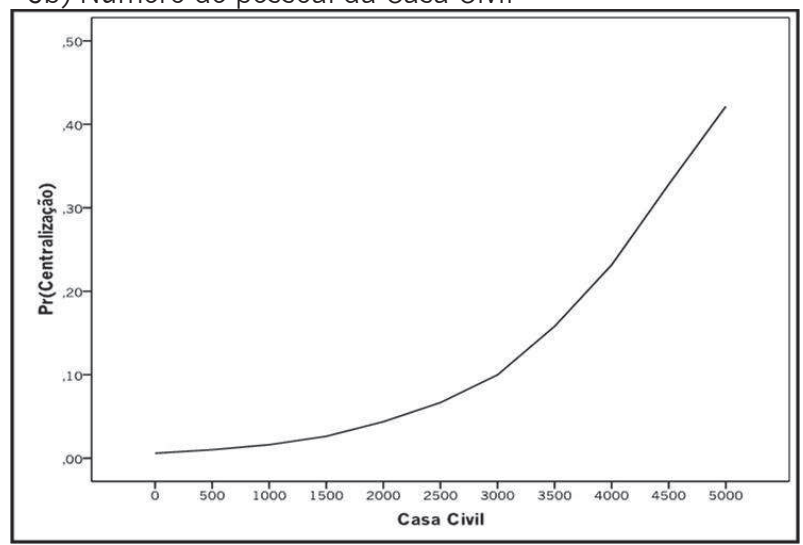

6c) Número de Ministros

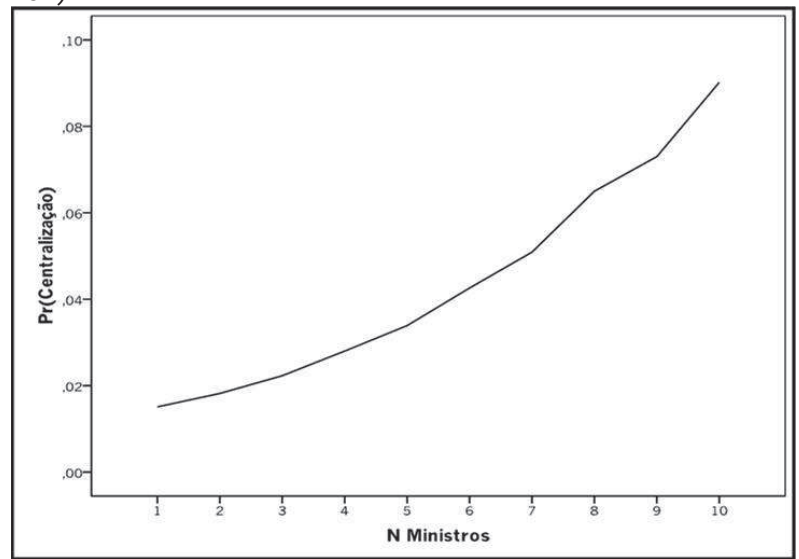

Fonte: Elaboração própria. 
Os Gráficos 6a, 6b e 6c apresentam a probabilidade predita de centralização com foco em três das quatro varáveis centrais do modelo: distância ideológica, número de pessoal da Casa Civil e número de ministros envolvidos na decisão, respectivamente. Força legislativa, a quarta variável principal do modelo, não foi analisada por não alcançar significância estatística nos modelos apresentados anteriormente. Como já identificado na Tabela 1, quanto maior a distância ideológica dos ministros maior a probabilidade de centralização. 0 Gráfico 6 a mostra que a probabilidade de centralização é 0.15 quando a soma das distâncias atinge o valor 10. O aumento do número de pessoal da Casa Civil (Gráfico 6b), medida de institucionalização do órgão de apoio direto do Presidente, aumenta significativamente a probabilidade de centralização, chegando à probabilidade de 0.40 . Por último, o número de ministros envolvidos na formulação da iniciativa legislativa (Gráfico 6c) também afeta a probabilidade de centralização, apresentando probabilidade de 0.10 quando 10 ministros participam da elaboração de uma iniciativa legislativa.

A Tabela 1 e os Gráficos 6a, 6b e 6c permitem a interpretação substantiva dos coeficientes e também indicar o efeito das variáveis de interesse sobre a probabilidade de centralização. Dito isto, distância ideológica, número de ministros e institucionalização da Casa Civil parecem ser importantes para entender a decisão do Presidente quanto à formulação de sua agenda legislativa. Contudo, a variável força legislativa, uma das principais do modelo teórico, não apresentou o resultado esperado, indicando que a quantidade de cadeiras no Legislativo não é uma medida adequada para avaliar a importância dos partidos na formulação da agenda legislativa do Executivo.

Tais resultados, de forma alguma, caracterizam-se como conclusivos para o entendimento da dinâmica interna do Poder Executivo. Busca-se apenas contribuir para a problematização do Poder Executivo como ator complexo, arena de decisões na qual a extensão do papel da coalizão ainda merece ser avaliada. Importante contribuição nesse sentido também vem sendo trabalhada por Rennó e Gaylord (2012).

Algumas ressalvas merecem ser destacadas. O presente artigo concentra-se em um pequeno aspecto do processo de formulação da agenda legislativa do Poder Executivo: a autoria dos projetos. Nesse sentido, muitos aspectos permanecem inexplorados, principalmente o papel da Presidência em geral e da Casa Civil em particular de controlar a produção legislativa dos Ministérios. Isto porque a Presidência formular um projeto mostra-se como um caso extremo de centralização. A centralização pode aparecer como a supervisão ou o controle continuado do processo decisório dos projetos ou ainda na forma de "veto" a projetos dos ministros, isto é, projetos que nem chegam a ser enviados ao Congresso. A total extensão do grau de centralização ainda merece devido estudo para a compreensão do processo de formulação de leis no Brasil.

\section{Conclusão}

Governos de coalizão são frequentes no Brasil desde o processo de redemocratização. 0 "presidencialismo de coalizão" brasileiro, resultado do sistema presidencialista e do multipartidarismo, manteve sua estabilidade e gerou altas taxas de sucesso para a agenda legislativa do Presidente. Este artigo buscou contribuir para o debate trazendo a discussão para dentro do Poder Executivo. Nesse sentido, qual o papel dos ministros e qual o papel da Presidência na produção legislativa do Executivo? 
BATISTA, M. O poder no Executivo: uma análise do papel da Presidência e dos Ministérios...

Analisando a autoria das iniciativas legislativas, foi possível observar que a grande maioria dos projetos tem sua origem nos ministérios. Desta forma, os benefícios da produção legislativa descentralizada nos ministérios, como a expertise dos ministros na área específica que chefiam e o controle de informação privilegiada, sobressaem-se aos seus custos, como a diminuição do controle sobre as decisões do governo. Contudo, um número não desprezível de projetos foi centralizado na Presidência. Por quê?

Um modelo de regressão logística para eventos raros foi estimado para entender os fatores explicativos da centralização. As principais hipóteses foram que o aumento na distância ideológica entre o Presidente e os ministros, o número de atores envolvidos e o fortalecimento da Casa Civil aumentariam a probabilidade de centralização, enquanto o aumento na força legislativa do partido do ministro afetaria negativamente a probabilidade de centralização. Os resultados indicaram que o número de atores, o fortalecimento da Casa Civil e, em menor grau, a distância ideológica importam para o entendimento da escolha do Presidente quanto ao processo de produção de leis.

Tais resultados apenas indicam caminhos e ideias para o entendimento do processo decisório no Executivo. Com muitas limitações, mais do que trazer respostas conclusivas, o presente artigo buscou contribuir para o crescimento da discussão sobre essa instituição central que é o Poder Executivo, analisando seus processos internos e problemas de delegação e coordenação, que mostram que o Executivo não se resume ao Presidente da República.

\section{Referências Bibliográficas}

Amorim Neto, O. Presidencialismo e Governabilidade nas Américas. Rio de Janeiro: Editora FGV, 2006.

Cheibub, J. A.; PrZeworski, A.; SAIEGH, S. "Governos de Coalizão nas Democracias Presidencialistas e Parlamentaristas". DADOS - Revista de Ciências Sociais, Rio de Janeiro, vol. 45, n² 2, p. 187-218, 2002.

COASE, R. "The Nature of the Firm". Economica New Series, Londres, vol. 4, n. 16, 1937, p. 386-405.

The Institutional Structure of Production. In: Menard, C. e ShIRLEY, M. (eds.). A Handbook of New Institutional Economics. Netherlands: Springer, 2005.

Edwards, G. C.; Kessel, J.; Rockman, B. Researching the Presidency: vital questions, new approaches. Pittsburgh: University of Pittsburgh Press, 1993.

EPSTEIN, D.; O'HALloRAn, S. Delegating Powers: a transaction cost politics approach to policy making under separate powers. Cambridge: Cambridge University Press, 1999

FIgueIRedo, A.; LIMongl, F. Executivo e Legislativo na Nova Ordem Constitucional. Rio de Janeiro: Editora FGV, 2001.

"Governments Coalitions in Brazilian Democracies". Brazilian Journal of Political Science, São Paulo, vol. 1,

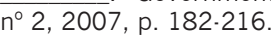

HowelL, W. Power Without Persuasion: the politics of direct presidential action. New Jersey: Princeton University Press, 2003.

INÁCIO, M. "Entre Presidir e Coordenar: presidência e gabinetes multipartidários no Brasil". Paper preparado para apresentação no $3^{\circ}$ Encontro Latino-Americano de Ciência Política. Campinas - Brasil, 2006.

KING, G. "Pseudo R² on Relogit" [online]. Relogit Mailing List served by Harvard-MIT Data Center, 2003. Disponível em: <https://lists.gking.harvard.edu/pipermail/relogit/2003-January/000048.html>. Acesso em: 12 jun. 2012. 
KING, G.; ZENG, L. Estimating Absolute, Relative, and Attributable Risks in Case-Control Studies [Online]. Department of Government, Harvard University, 1999, Disponível em: <http://GKing. Harvard.Edu>. Acesso em: 05 jan.2011.

. “Logistic Regression in Rare Events Data”. Political Analysis, vol. 9, p. 137-163, 2001.

LAMEIRÃo, C. "A Casa Civil como instituição do Executivo federal". Desigualdade e Diversidade, Rio de Janeiro, Ed. Especial, p. 143:184, 2011.

LAVER, M.; ShePsle, K. "Coalitions and Cabinet Government". The American Political Science Review, Washington, vol. 84, $n^{\circ}$, p. 873.890, 1990.

.; __ Cabinet Ministers and Parliamentary Government. Cambridge: Cambridge University Press, 1994.

MAINWARING, S. "Presidentialism, multipartism and democracy: the difficult combination". Comparative political Studies, $26, n^{\circ} 2$, July 1993.

MARTINEZ-GALLARDO, C. Inside the Cabinet: the influence of ministers in the policymaking process. In: SCARTASCINI, C.; SteIn, E.; Tommasi, M. (eds.). How Democracy Works: Political Institutions, Actors, and Arenas in Latin American Policymaking, 1. Washington: Inter-American Development Bank, p. 119.45, 2010.

MénARd, C. A New Institutional Approach to Organization. In: MÉnARd, C.; SHIRLEY, M. (eds.). A Handbook of New Institutional Economics. Netherlands: Springer, 2005.

.; ShIRley, M. Introduction. In: MÉnARd, C.; SHIRLEY, M. (eds.). A Handbook of New Institutional Economics. Netherlands: Springer, 2005.

Moe, T. The Politicized Press. In: Chubb, J.; Peterson, P. (eds.). The New Directions in American Politics. Washington: The Bookings Institution, 1985.

MulleR, W.; StRom, K. Coalition Governments in Western Europe. Oxford: Oxford University Press, 2000.

Muller, W.; Bergman, T.; Strom, K. Coalition theory and cabinet governance: an introduction. In: Strom, K.; Muller, W.; Bergman, T. (eds.). Cabinets and coalition bargain: the democratic life cycle in Western Europe. Oxford: Oxford University Press, 2010.

Neustadt, R. Presidential Power: the politics of leadership. New York/London: John Wiley \& Sons, 1961.

NORTH, D. Institutions, Institutional Change, Economic Performance. Cambridge: Cambridge University Press, 1990.

PolsBy, N. "The Institutionalization of the U.S. House of Representatives". The American Political Science Review, Washington, vol. 62, $\mathrm{n}^{\circ} 1$, p. 144-168, 1968.

PraçA, S.; Freitas, A.; Hoepers, B. "Political Appointments and Coalition Management in Brazil, 2007-2010". Journal of Politics in Latin America, Hamburgo, vol. 3, n² 2, p. 141-172, 2011.

RenNó, L.; GAYLORD, S. "Behind Closed Doors: Cabinet Authorship of Legislative Proposals in a Multiparty Presidential System". Paper prepared for presentation at the XXII World Congress of Political Science, Madrid, 2012.

Rudalevige, A. Managing the President's Program: presidential leadership and legislative policy formulation. New Jersey: Princeton University Press, 2002.

TOMZ, M.; KING, G.; ZeNG, L. RELOGIT: Rare Events Logistic Regression. Version 1.1 [Online]. Harvard University, $1^{\circ}$ Out. 1999. Disponível em: <http://gking.harvard.edu/>. Acesso em: 05 jan. 2011.

WEINGAST, B.; MARShALL, W. "The Industrial Organization of Congress or Why Legislatures Like Firms Are Not Organized as Markets". The Journal of Political Economy, Chicago, vol. 96, n 1, p. 132-163, 1988.

WILLIAMSON, O. "Transaction-Cost Economics: the governance of contractual relations". Journal of Law and Economics, Chicago, vol. 22, n², p. 233-261, 1979.

. "Public and Private Bureaucracies: a transaction cost economic perspective". The Journal of Law, Economics and Organization, Oxford, vol. 15, $\mathrm{n}^{\circ} 1$, p. 306-342, 1999.

"The New Institutional Economics: taking stock, looking ahead". Journal of Economic Literature, Pittsburgh, vol. $38, n^{\circ} 3$, p. 595.613, 2000. 

<web.cenet.org.cn/upfile/19959.pdf>. Acesso em: 05 jan.2011.

Transaction Cost Economics. In: MÉNARD, C.; SHIRLEY, M. (eds.). A Handbook of New Institutional Economics. Netherlands: Springer, 2005.

Zucco, C.; LAUderdale, B. "Ideal Point Estimates of Brazilian Legislators"; 2002 [Online]. Disponível em: <http://hdl.handle.net/1902.1/15572 UNF:5:PJwLMB9eeufBTxEGSykKbA== V2 [Version]>. Acesso em: 05 jan.2010.

"Distinguishing Between Influences on Brazilian Legislative Behavior". Legislative Studies Quarterly, Londres, vol. 36, $n^{\circ}$ 3, p. 363-396, 2011.

Anexo

Evolução da Casa Cívil

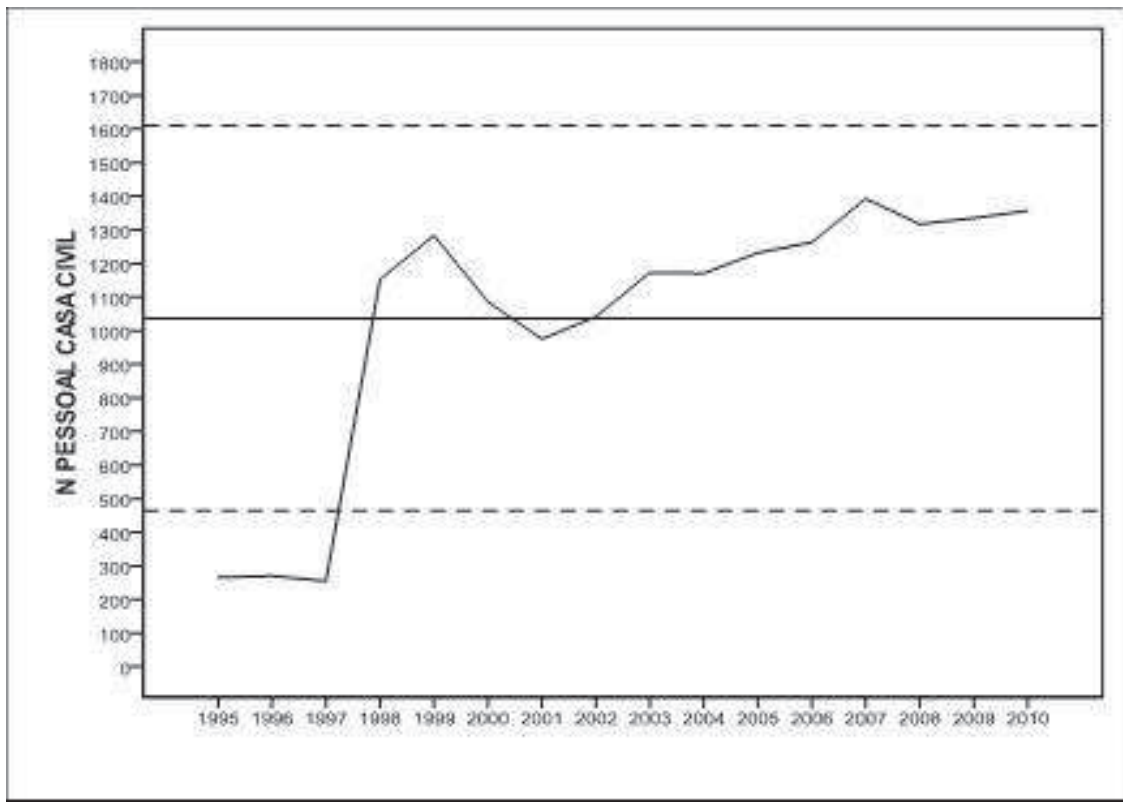

Mariana Batista - mariana.bsilva@gmail.com

Submetido à publicação em agosto de 2012.

Versão final aprovada em outubro de 2013. 